BLACKWELL

\title{
Experience of health care services after a suicide attempt: Results from an online survey
}

\begin{tabular}{|r|l|}
\hline Journal: & Suicide and Life-Threatening Behavior \\
\hline Manuscript ID & 2017-SLTB-0037.R1 \\
\hline Wiley - Manuscript type: & Original Article \\
\hline Complete List of Authors: & n/a \\
\hline & $\begin{array}{l}\text { Shand, Fiona; University of New South Wales, ; Black Dog Institute, } \\
\text { Batterham, Philip; Australian National University, Centre for Mental Health } \\
\text { Research } \\
\text { Chan, Jade; University of New South Wales } \\
\text { Pirkis, Jane; University of Melbourne, Melbourne School of Population and } \\
\text { Global Health } \\
\text { Spittal, Matthew; University of Melbourne } \\
\text { Woodward, Alan; Lifeline Australia, Lifeline Research Foundation } \\
\text { Christensen, Helen; Black Dog Institute, Department of Medicine }\end{array}$ \\
\hline Keywords: & \begin{tabular}{l} 
suicide attempt, health care \\
\hline Abstract:
\end{tabular} \\
& $\begin{array}{l}\text { Failure to provide follow-up care after a suicide attempt is associated with } \\
\text { increased risk of re-attempt. This online survey examined the experiences } \\
\text { of patients of the Australian health system after a suicide attempt. Just } \\
\text { over half of the participants had a psychiatric assessment within one week } \\
\text { of their attempt. Fewer than half believed they had been offered enough } \\
\text { help. Low service satisfaction was associated with lower help-seeking } \\
\text { intentions. Support for individuals who have made a suicide attempt needs } \\
\text { to be enhanced, and an integrated approach to care is required, including } \\
\text { improved referral pathways and staff attitudinal change. }\end{array}$ \\
\hline
\end{tabular}




\section{Experience of health care services after a suicide attempt: Results from an online survey}

Fiona L Shand ${ }^{1,2}$, Philip J Batterham ${ }^{3}$, Jade KY Chan ${ }^{2}$, Jane Pirkis ${ }^{4}$, Matthew J Spittal ${ }^{4}$, Alan Woodward $^{5}$, Helen Christensen ${ }^{1,2}$

${ }^{1}$ Black Dog Institute, Sydney, Australia

${ }^{2}$ University of New South Wales, Sydney, Australia

${ }^{3}$ National Institute of Mental Health Research, The Australian National University, Canberra, Australia

${ }^{4}$ Melbourne School of Population and Global Health, The University of Melbourne, Australia

${ }^{5}$ Lifeline, Sydney, Australia

Corresponding Author: Fiona Shand, Black Dog Institute, Hospital Rd, Randwick NSW 2231, AUSTRALIA; fionas@unsw.edu.au

Word count: 2,833 (excluding tables, references and abstract) 


\begin{abstract}
Failure to provide follow-up care after a suicide attempt is associated with increased risk of re-attempt. This online survey examined the experiences of patients of the Australian health system after a suicide attempt. Just over half of the participants had a psychiatric assessment within one week of their attempt. Fewer than half believed they had been offered enough help. Low service satisfaction was associated with lower help-seeking intentions. Support for individuals who have made a suicide attempt needs to be enhanced, and an integrated approach to care is required, including improved referral pathways and staff attitudinal change.
\end{abstract}




\section{INTRODUCTION}

A suicide attempt leads to a range of responses from the individual, their family, and the health system. For some people, it is a turning point that changes the way they see life. For others, it induces a sense of failure, hopelessness, shame, anger, and disappointment (Chesley \& Loring-McNulty, 2003). The response of the health system at this time is important, yet it could best be described as mixed, with many patients reporting difficult and often stigmatising experiences with health services (SANE Australia, 2015).

The risk of a repeat attempt is high with hospital-treated suicide attempt as the strongest risk factor for subsequent suicide (Carter et al., 2002; Carroll et al., 2014). Repetition of suicide attempt in those with a history of a previous suicide attempt is around 30\% (Carter et al., 2002). The period shortly after discharge from hospitalisation for a suicide attempt or psychiatric treatment is particularly risky. In Australia, over one-third of Western Australian men and over half the women who died by suicide between 1986 and 2005 had previously been hospitalised for self-inflicted injuries (Stokes, 2012). Of the patients who died by suicide after hospital discharge, $15 \%$ of men and $20 \%$ of women died by suicide on the day of discharge. A UK study identified that $47 \%$ of suicides post-discharge occurred within the first month, with $43 \%$ of those occurring before the deceased's first follow-up appointment (Hunt et al., 2009). Thus, failure to provide rapid and effective follow up after a suicide attempt is a missed opportunity and is associated with increased risk of further suicide attempts and suicide (Meehan et al., 2006).

A number of studies have demonstrated the association between care received after a suicide attempt and risk for a further attempt. A reduction in professional care is strongly associated with suicide (Appleby et al., 1999). Conversely, effective discharge planning and comprehensive care after discharge from ED and psychiatric inpatient facilities appears to reduce subsequent suicidal behaviour and suicide deaths (Bickley et al., 2013; Luxton, June, \& Comtois, 2013). improve adherence to aftercare, and decrease symptomology (Steffen et al., 2009). Continuity of care models may be 
effective (Hvid et al., 2011), and brief contact interventions show promise in reducing the number of repetitions (Milner et al., 2015).

Longitudinal studies of health service practices also indicate that delivering follow-up treatment reduces the risk of suicide. A study of 89 mental health services across England and Wales reported a reduced rate of suicide when suicide prevention recommendations (assertive outreach, crisis teams, post-discharge follow-up, addressing treatment non-compliance) were implemented (While et al., 2012). Implementation was variable: in the lower-performing services, the proportions of patients receiving a psychosocial assessment or mental health referral were as low as $22 \%$ and $11 \%$ respectively (Cooper et al., 2013).

Qualitative studies involving patients and health service staff have also found patients receive inconsistent referrals and care from health services (SANE Australia, 2015; Saunders et al., 2012; Taylor et al., 2009). Among those who receive a referral, some are expected to initiate the after-care process themselves, some did not receive follow-up as promised, and others reported up to 12 weeks' delay between discharge and follow-up care (Taylor et al., 2009). Even when patients are referred to mental health services, gaining access to help can be problematic (Rhodes et al., 2009). These findings are concerning: making decisions and taking action immediately after a suicide attempt is often difficult, and futile attempts to access help can exacerbate feelings of hopelessness and isolation, which may contribute to increased suicide risk.

It is clear then that the response of health services after a suicide attempt is critical. In order to examine the current gaps in the health service response to suicide attempt, this paper examines, through an online survey, the experiences with Australian health services of people who have made a suicide attempt. Specifically, it examines:

1. What type of and how much care people received after a suicide attempt,

2. How satisfied patients were with their health service experience, and,

3. Predictors of future help-seeking for suicidality. 
Page 5 of 20

Suicide and Life-Threatening Behavior

4 


\section{Methods}

\section{Procedure}

Two online surveys were conducted to collect views about the health system from (1) those who had made a suicide attempt and (2) their caregivers. This paper reports only on the survey of those who had made a suicide attempt. We sought information about participants' histories of suicide attempts and their health service experiences. The online survey took approximately 20 minutes to complete. The surveys were completed between December 2013 and June 2014.

\section{$\underline{\text { Participants and recruitment }}$}

The survey was completed by 112 individuals who had made a suicide attempt. Inclusion criteria were assessed via a series of questions completed online, and included: had made a suicide attempt between at least one month and no more than 18 months prior; resident of Australia; and aged 18 years or over. Participants were recruited via social media (Facebook and Twitter) and websites of the Black Dog Institute and consumer organisations. Participants provided ratings of their mood state before and after the survey. Ethics approval was granted by the University of New South Wales Human Research Ethics Committee (HC13298).

\section{$\underline{\text { Survey design and content }}$}

The survey covered a number of domains, including: demographic characteristics; self-reported lifetime diagnosis of psychiatric disorders; and lifetime number of suicide attempts and hospital-treated suicide attempts. Participants were then asked to report on their most recent suicide attempt, including whether they had received treatment. If they had received treatment, they were asked about their first, second, and third points of contact with the health system, invited to complete a range of satisfaction measures with these services, and asked to indicate how they perceived the adequacy of the support offered at different time points.

$\underline{\text { Statistical analysis }}$ 
Descriptive statistics, including medians, means, and frequencies were used to describe participants and their health service experience. All statistical analysis was carried out in SPSS v20 (IBM Corp, Chicago IL, USA). Univariate analysis using chi-square statistics was used to test variables associated with (a) service use after the most recent attempt, (b) satisfaction with the three most commonly used services: EDs, emergency services and psychiatrists, and (c) likelihood of revealing future suicidality to a health professional. Variables tested were gender, marital status, education, employment, diagnosis, number of attempts, time of last attempt, method, previous disclosure of ideation, future disclosure of ideation, and age. 


\section{Results}

\section{$\underline{\text { Participant characteristics }}$}

The median participant age was 31 years (range 18-59 years). The majority of participants were female, in paid employment, not in a live-in relationship, and reported a current or lifetime psychiatric diagnosis(Table 1). The mean number of lifetime suicide attempts and hospital attendances following an attempt was 3.0. One quarter of the sample had made one attempt during their lifetime and one quarter had made five or more. The most common method used in the most recent attempt was selfpoisoning $(60 \%)$ followed by cutting $(20 \%)$. Just over half required medical treatment for physical injuries following the most recent attempt.

\section{Insert Table 1 about here}

\section{Health services used}

Most (96\%) were in contact with a health service in the week following their most recent suicide attempt; 57\% had a psychiatric assessment within one week of this attempt. The first point of health service contact was most commonly emergency services or ED (Table 2).

Two-thirds did not have contact with a second health service and $84 \%$ had no contact with a third service. The most commonly used second health service was a psychiatrist, followed by ED, psychologist, or other mental health worker. When all contacts were examined, $27 \%$ of participants had contact with emergency services, followed by ED (24\%), psychiatrist (14\%), or telephone help line $(13 \%)$.

Of those whose first contact was with emergency services, $58 \%$ had their next contact with ED, 22\% with a mental health professional, and 5\% with a GP. For those whose first contact was with ED, 25\% saw a psychiatrist as their next point of contact, $19 \%$ had no other care, $13 \%$ saw a GP, and $12 \%$ saw another mental health professional. 
Employment status was the only variable associated with ED and emergency services use (as the first point of contact): those identifying as a student, retired, engaged in home duties, or working in volunteer positions were more likely to utilise the emergency department $\left(\chi^{2}=9.42, p=0.024\right)$ and emergency services $\left(\chi^{2}=9.2, p=0.027\right)$ than those not currently in paid employment. Only higher educational status $\left(\chi^{2}=6.61, p=0.037\right)$ and previously reporting ideation $\left(\chi^{2}=8.86, p=0.003\right)$ to a health professional were univariately associated with psychiatrist use.

\section{$\underline{\text { Views of services }}$}

Participants were asked if they believed they had been offered enough help (1) immediately after the suicide attempt, (2) after leaving the hospital or treatment facility, and (3) in the six months following the suicide attempt. At each point, less than half (45\%, 41\% and $44 \%$ respectively) agreed that they had been offered enough help. The most commonly endorsed reason for not being offered enough help was 'the attitude of staff members towards me was poor' (26\%; Table 3$)$.

\section{Insert Table 3 about here}

Participants were also asked to rate their satisfaction with each type of service, the quality of the service, staff attitudes, and staff knowledge (Table 4). Overall, general practitioners were rated highest, and crisis teams and EDs lowest. Participants reported that lower satisfaction was due to poor staff attitudes towards them, inadequate staff knowledge about suicide, being discharged too rapidly, not being followed up after discharge from hospital, and not having their emotional distress attended to. Three quarters of those who saw a mental health professional rated their experience as somewhat or very helpful. A mean $>3.0$ in Table 3 indicates that the average respondent found the service to be unsatisfactory on that criterion. 


\section{Insert Table 4 about here}

\section{$\underline{\text { Help-seeking behaviour and intentions }}$}

Forty three per cent of participants reported telling a health professional that they were experiencing suicidal thoughts or had a suicide plan before their most recent attempt. Those who did not tell a health professional said that they did not want to be stopped (28.6\%), felt ashamed (25.9\%), did not think anyone could help them (23.2\%), or did not want to be admitted to inpatient care $(16.1 \%)$. More than half $(57 \%)$ said that if they had suicidal thoughts or plans in the future they would tell a health professional. In univariate analysis, those who said they would reveal future suicidality to a health professional reported higher overall satisfaction (mean 2.5 vs $3.2, \mathrm{t}=3.4, \mathrm{p}<0.001$ ), quality of care (mean 2.3 vs 3.0, $\mathrm{t}=3.6, \mathrm{p}<0.001$ ), staff attitudes (mean 2.4 vs $3.0, \mathrm{t}=2.4, \mathrm{p}=0.019$ ) and staff knowledge (mean 2.1 vs $2.6, \mathrm{t}=2.5, \mathrm{p}=0.014$ ). In terms of experiences with specific services, only satisfaction with $\operatorname{ED}\left(\chi^{2}=8.1, \mathrm{p}=0.005\right)$ and emergency services $\left(\chi^{2}=5.6, \mathrm{p}=0.018\right)$ had significant associations with revealing future suicidality.

\section{$\underline{\text { Patient involvement in decision-making }}$}

Most participants (59\%) reported that they were involved in making decisions about what treatment they needed. Of those who were not involved, three quarters said that they would have liked to be involved in making treatment decisions. Of those who were involved in making decisions about their treatment, $73 \%$ said that it was helpful or very helpful, $21 \%$ were unsure, and $6 \%$ said it was unhelpful. 


\section{Discussion}

In this study of people's experience of health services following a suicide attempt, emergency services and ED were the most commonly reported first point of contact. With only one-third of participants reporting contact with a second health service, and less than half of all participants believing they had received enough help, a valuable opportunity to provide effective treatment, and thereby reduce the risk of a subsequent attempt, is being missed. This study also calls into question the quality of treatment received through some services, with lower levels of satisfaction and poorer ratings of staff attitudes and knowledge for hospital EDs and crisis teams. This is concerning, since those patients who had a poorer health service experience also reported lower likelihood of disclosing future suicidality.

Consistent with overseas studies, just over half of the participants reported receiving a thorough assessment in the week following their suicide attempt (Cooper et al., 2013). Furthermore, many patients reported leaving the hospital without referral to follow up care. These strategies have been shown to reduce the risk of a subsequent suicide or suicide attempt: failure to conduct comprehensive psychosocial assessments, to arrange referrals to specialist care, and to provide clear discharge plans may result in a high rate of ED re-presentations within a short time frame (Hickey et al., 2001; Kapur et al., 2004; Kuehl, Nelson, \& Collings, 2012). Yet, despite efforts to ensure patients receive referrals to follow up care upon discharge in most Australian jurisdictions, change is slow and inconsistent. Our data linkage study found that only $41 \%$ of all patients admitted to New South Wales hospitals for DSH between 2005 and 2011 received follow up treatment from the public health system in the month following hospital discharge (Spittal et al., 2016). The participants in this survey had made a suicide attempt in the previous 18 months and completed surveys between December 2013 and June 2014, and so reflect recent health service experiences.

There are evidence-based options available to hospitals for patients who have made a suicide attempt, including assertive follow up, continuity of care models, and brief contact interventions (Hvid et al., 2011; Milner et al., 2015). The evidence base for emergency services interventions is less clear and the role of emergency services personnel as first responders to mental health and suicidal crises is often 
debated. Police services in some Australian jurisdictions have officers who are trained in responding to a mental health crisis and some involve a clinician in the process, but the published evaluation of these interventions has focussed more on policing outcomes than patient outcomes (Herrington \& Pope, 2014; Lee et al., 2015).

The attitudes and beliefs of health service staff towards people who have made a suicide attempt have been reported in a systematic review, which found that nurses and doctors tend to have negative and un-empathetic attitudes toward patients who self-harm (Saunders et al., 2012). Although the review did not find any difference between older and newer studies, a more recent study from Norway found more positive attitudes amongst health staff (Norheim, Grimholt, \& Ekeberg, 2013). In the current study, poor staff attitude was reported against a number of questions. Routine training of hospital staff in suicide prevention is required, with evidence that training leads to long-term improvements in staff attitude and knowledge towards patients with suicidality (Saunders et al., 2012). The need for a different approach by health service staff is particularly critical for patients with multiple hospital presentations for DSH, as was the case for many participants in this study. For this population, DSH might be better acknowledged as a long-term health problem with a view to managing the condition in a proactive and structured way, rather than providing symptom-focused, acute care (Poustie \& Neville, 2004).

The main limitation of this study was the convenience sampling used and therefore, the risk that the results are not broadly representative of all patients receiving care following a suicide attempt. Relatedly, our sample was small. It is possible that those who had negative experiences with the health system following a suicide attempt may have been more likely to complete the survey. Nevertheless, the health service concerns (lack of follow up contact and treatment, negative attitudes from staff) described by participants in this study are consistent with those of previous studies (Cooper et al., 2013; Rhodes et al., 2009; SANE Australia, 2015).

There is now good evidence to recommend psychosocial assessment and follow up appointments with people who have had a suicide attempt. This study shows that, too often, this is missing, as is an 
empathic response to the emotional, social and psychiatric needs of a person who has attempted suicide. In light of these findings, we suggest that the support for individuals who have made a suicide attempt and their families be enhanced, with particular attention directed to the emotional and psychosocial aspects of a suicide attempt. Coordinated care after a suicide attempt is required, including a care coordinator who can help patients to navigate the clinical and non-clinical elements of their care, data driven improvements to better track patients, their treatment and treatment outcomes, systems changes that allow patients to be followed-up assertively, and staff training/attitudinal change. Patients and caregivers should be encouraged to be involved in treatment planning prior to discharge and with their general practitioner. A coordinated approach to health care should be informed by data collection and monitoring so that early identification of lapses in adherence to treatment, or changes in clinical assessments, occurs. Evaluation of post-acute release services would also be better informed through the collection and analysis of such data. The present study demonstrates specific shortcomings of the health system at times of crisis, and identifies a number of processes that would improve the health care experience for people who have attempted suicide.

\section{Acknowledgements}

This study was supported by funding from the Australian National Mental Health Commission. The authors gratefully acknowledge the participants who completed the survey. 


\section{REFERENCES}

Appleby, L., Dennehy, J. A., Thomas, C. S., Faragher, E. B., \& Lewis, G. (1999). Aftercare and clinical characteristics of people with mental illness who commit suicide: a case-control study. The Lancet, 353, 1397-1400. doi: http://dx.doi.org/10.1016/S0140-6736(98)10014-4

Bickley, H., Hunt, I. M., Windfuhr, K., Shaw, J., Appleby, L., \& Kapur, N. (2013). Suicide within two weeks of discharge from psychiatric inpatient care: a case-control study. Psychiatr Serv, 64, 653-659. doi: 10.1176/appi.ps.201200026

Carroll, R., Metcalfe, C., Gunnell, D., \& Carter, G. (2014). Hospital presenting self-harm and risk of fatal and non-fatal repetition: Systematic review and meta-analysis. PLoS ONE, 9, e89944.

Carter, G. L., K.A., C., Bryant, J. L., \& Whyte, I. M. (2002). Can the Edinburgh Risk of Repetition Scale predict repetition of deliberate self-poisoning in an Australian clinical setting? . Suicide and Life Threatening Behavior, 32, 230-239.

Chesley, K., \& Loring-McNulty, N. E. (2003). Process of Suicide: Perspective of the Suicide Attempter. Journal of the American Psychiatric Nurses Association, 9, 41-45. doi: $10.1016 / \mathrm{s} 1078-3903(03) 00052-1$

Cooper, J., Steeg, S., Bennewith, O., Lowe, M., Gunnell, D., House, A., et al. (2013). Are hospital services for self-harm getting better? An observational study examining management, service provision and temporal trends in England. BMJ Open, 3. doi: 10.1136/bmjopen-2013-003444

Herrington, V., \& Pope, R. (2014). The impact of police training in mental health: an example from Australia. Policing and Society, 24, 501-522. doi: 10.1080/10439463.2013.784287

Hickey, L., Hawton, K., Fagg, J., \& Weitzel, H. (2001). Deliberate self-harm patients who leave the accident and emergency department without a psychiatric assessment: A neglected population at risk of suicide. Journal of Psychosomatic Research, 50, 87-93. doi: http://dx.doi.org/10.1016/S0022-3999(00)00225-7

Hunt, I. M., Kapur, N., Webb, R., Robinson, J., Burns, J., Shaw, J., et al. (2009). Suicide in recently discharged psychiatric patients: a case-control study. Psychological Medicine, 39, 443-449. 
Hvid, M., Vangborg, K., Sørensen, H. J., Nielsen, I. K., Stenborg, J. M., \& Wang, A. G. (2011). Preventing repetition of attempted suicide-II. The Amager Project, a randomized controlled trial. Nordic journal of psychiatry, 65, 292-298.

Kapur, N., Cooper, J., Hiroeh, U., May, C., Appleby, L., \& House, A. (2004). Emergency department management and outcome for self-poisoning: a cohort study. General Hospital Psychiatry, 26, 36-41. doi: http://dx.doi.org/10.1016/j.genhosppsych.2003.06.002

Kuehl, S., Nelson, K., \& Collings, S. (2012). Back so soon: rapidfire-presentations to the emergency department following intentional self-harm. Journal of the New Zealand Medical Association, $125,70-79$.

Lee, S. J., Thomas, P., Doulis, C., Bowles, D., Henderson, K., Keppich-Arnold, S., et al. (2015). Outcomes achieved by and police and clinician perspectives on a joint police officer and mental health clinician mobile response unit. Int J Ment Health Nurs, 24, 538-546. doi: 10.1111/inm. 12153

Luxton, D. D., June, J. D., \& Comtois, K. A. (2013). Can postdischarge follow-up contacts prevent suicide and suicidal behavior? A review of the evidence. Crisis, 34, 32-41. doi: 10.1027/0227$5910 / \mathrm{a} 000158$

Meehan, J., Kapur, N., Hunt, I. M., Turnbull, P., Robinson, J., Bickley, H., et al. (2006). Suicide in mental health in-patients and within 3 months of discharge. National clinical survey. $\mathrm{Br} J$ Psychiatry, 188, 129-134. doi: 10.1192/bjp.188.2.129

Milner, A., Carter, G., Pirkis, J., Robinson, J., \& Spittal, M. (2015). Letters, green cards, telephone calls and postcards: systematic and meta-analytic review of brief contact interventions for reducing self-harm, suicide attempts and suicide. British Journal of Psychiatry, 206, 184-190.

Norheim, A. B., Grimholt, T. K., \& Ekeberg, Ø. (2013). Attitudes towards suicidal behaviour in outpatient clinics among mental health professionals in Oslo. BMC Psychiatry, 13, 1-10. doi: $10.1186 / 1471-244 x-13-90$

Poustie, A., \& Neville, R. G. (2004). Deliberate self-harm cases: a primary care perspective. Nursing standard, 18, 33-36. 
Rhodes, K. V., Vieth, T. L., Kushner, H., Levy, H., \& Asplin, B. R. (2009). Referral without access: for psychiatric services, wait for the beep. Annals of emergency medicine, 54, 272-278.

SANE Australia, \& University of New England. (2015). Lessons for Life. The experiences of people who attempt suicide: A qualitative research report. Canberra: SANE Australia.

Saunders, K. E. A., Hawton, K., Fortune, S., \& Farrell, S. (2012). Attitudes and knowledge of clinical staff regarding people who self-harm: A systematic review. Journal of Affective Disorders, 139, 205-216. doi: http://dx.doi.org/10.1016/j.jad.2011.08.024

Spittal, M. J., Shand, F., Christensen, H., Brophy, L., \& Pirkis, J. (2016). Community mental health care after self-harm: A retrospective cohort study. Australia and New Zealand Journal of Psychiatry, 51. doi: 10.1177/0004867416676366

Steffen, S., Kösters, M., Becker, T., \& Puschner, B. (2009). Discharge planning in mental health care: a systematic review of the recent literature. Acta Psychiatrica Scandinavica, 120, 1-9. doi: 10.1111/j.1600-0447.2009.01373.x

Stokes, B. (2012). Review of the admission or referral to and the discharge and transfer practices of public mental health facilities/services in Western Australia. Perth, WA: Department of Health, Western Australia and the Mental Health Commission.

Taylor, T. L., Hawton, K., Fortune, S., \& Kapur, N. (2009). Attitudes towards clinical services among people who self-harm: systematic review. Br J Psychiatr, 194. doi: 10.1192/bjp.bp.107.046425

Taylor, T. L., Hawton, K., Fortune, S., \& Kapur, N. (2009). Attitudes towards clinical services among people who self-harm: systematic review. The British Journal of Psychiatry, 194, 104-110.

While, D., Bickley, H., Roscoe, A., Windfuhr, K., Rahman, S., Shaw, J., et al. (2012). Implementation of mental health service recommendations in England and Wales and suicide rates, 1997-2006: a cross-sectional and before-and-after observational study. The Lancet, 379, 1005-1012. 


\section{Tables}

Table 1: Characteristics of participants

\begin{tabular}{|c|c|c|}
\hline Characteristics & $\begin{array}{l}\text { Number } \\
(\mathrm{N}=112)\end{array}$ & Percentage \\
\hline Gender $=$ Female & 90 & 80 \\
\hline Marital status $=$ Married/defacto & 41 & 37 \\
\hline Employment status $=$ Employed & 64 & 57 \\
\hline \multicolumn{3}{|l|}{ Education } \\
\hline Completed year 12 & 64 & 27 \\
\hline Completed trade or diploma & 34 & 30 \\
\hline Completed university degree or higher & 38 & 34 \\
\hline \multicolumn{3}{|l|}{ Living situation } \\
\hline Alone & 15 & 13 \\
\hline Family & 111 & 67 \\
\hline Friends/flatmates & 6 & 5 \\
\hline Other & 2 & 2 \\
\hline \multicolumn{3}{|l|}{ Psychiatric diagnoses (current or lifetime)* } \\
\hline Any psychiatric diagnosis & 106 & 95 \\
\hline Mood disorder (incl Bipolar disorder) & 90 & 80 \\
\hline Anxiety disorder (excl PTSD) & 62 & 57 \\
\hline Personality disorder & 20 & 18 \\
\hline Any psychotic disorder (incl. psychosis) & 2 & 2 \\
\hline Eating disorder & 13 & 12 \\
\hline Substance use disorder & 17 & 5 \\
\hline PTSD & 25 & 22 \\
\hline
\end{tabular}

*multiple responses were permitted 
Table 2: Points of contact with health services

\begin{tabular}{|c|c|c|c|}
\hline $\begin{array}{l}\text { Type of service - initial point of } \\
\text { contact }\end{array}$ & $\begin{array}{l}\text { First contact } \\
(\%) \\
n=95\end{array}$ & $\begin{array}{l}\text { Second contact } \\
(\%) \\
n=33\end{array}$ & $\begin{array}{l}\text { Third contact } \\
(\%) \\
n=15\end{array}$ \\
\hline Ambulance/police & 24 & 6 & 7 \\
\hline Emergency department & 20 & 12 & 0 \\
\hline Family/friend/neighbour/stranger & 17 & 3 & 0 \\
\hline Telephone helpline / crisis service & 10 & 3 & 7 \\
\hline General Practitioner & 4 & 9 & 13 \\
\hline Psychologist & 3 & 12 & 20 \\
\hline Psychiatrist & 1 & 27 & 20 \\
\hline Other mental health professional & 4 & 12 & 14 \\
\hline
\end{tabular}


Table 3: Reasons given for not being offered enough help after suicide attempt

\begin{tabular}{lll}
\hline Reason & n=112 & Percentage* \\
\hline The attitude of staff members towards me was poor & 29 & 26 \\
I was afraid to ask for help & 25 & 22 \\
I was afraid of what others would think of me & 24 & 21 \\
I didn't think anything could help & 24 & 17 \\
I couldn't afford the cost & 18 & 16 \\
I asked but didn't get the help & 112 & 13 \\
I didn't know where to get help & 13 & 11 \\
I already had support & 12 & 5 \\
I got help from another source & 6 & \\
\hline
\end{tabular}

\footnotetext{
*multiple responses were permitted
} 
Table 4: Satisfaction with and quality of services

\begin{tabular}{lccccc}
\hline Service (N) & $\mathbf{N}$ & $\begin{array}{c}\text { Satisfaction } \\
\text { with } \\
\text { services }^{\mathbf{a}}\end{array}$ & $\begin{array}{c}\text { Quality of } \\
\text { services }^{\mathbf{b}}\end{array}$ & $\begin{array}{c}\text { Staff } \\
\text { attitudes }^{\mathbf{c}}\end{array}$ & $\begin{array}{c}\text { Staff } \\
\text { knowledge }^{\mathbf{d}}\end{array}$ \\
\hline GP & 17 & 1.7 & 1.8 & 1.6 & 1.5 \\
Telephone helpline/crisis & 14 & 2.2 & 2.4 & 1.8 & 1.9 \\
service & 18 & 2.5 & 2.2 & 2.1 & 1.6 \\
Psychologist & $28-32$ & 2.5 & 2.3 & 2.3 & 2.3 \\
Emergency services & 30 & 2.7 & 2.2 & 1.9 & 1.6 \\
Psychiatrist & 13 & 2.7 & 2.0 & 2.2 & 1.9 \\
Mental health/social worker & 7 & 2.9 & 2.6 & 3.0 & 2.7 \\
General hospital department & & & & & \\
Suicide prevention/crisis & & 3.1 & 2.7 & 2.3 & 1.9 \\
team & 15 & 3.2 & 3.2 & 3.0 & 3.0 \\
Emergency Department & $39-41$ & & & & \\
\hline
\end{tabular}

a 1 (Extremely satisfied) - 5 (Not at all)

${ }^{\mathrm{b}} 1$ (Extremely well) - 5 (Not at all)

c 1 (Excellent) - 5 (Very poor)

${ }^{\mathrm{d}} 1$ (Very knowledgeable) - 5 (Not knowledgeable) 